\title{
As cores $u m$ mi masã no traçado das mãos de Feliciano Lana
}

\author{
Jaime Diakara, Dagoberto Lima Azevedo, Justino Sarmento Rezende, \\ Silvio Sanches Barreto, João Paulo Lima Barreto e Gilton Mendes dos \\ Santos
}

Gilton Mendes dos Santos (ed.)

\section{OpenEdition Journals}

Edição electrónica

URL: https://journals.openedition.org/jsa/18901

DOI: $10.4000 /$ jsa. 18901

ISSN: 1957-7842

\section{Tradução(ões):}

The colors of umuri masã in the brushstrokes of Feliciano Lana - URL : https:// journals.openedition.org/jsa/19228 [en]

Editora

Société des américanistes

\section{Edição impressa}

Data de publição: 15 dezembro 2020

Paginação: 259-268

ISSN: 0037-9174

\section{Refêrencia eletrónica}

Jaime Diakara, Dagoberto Lima Azevedo, Justino Sarmento Rezende, Silvio Sanches Barreto, João Paulo Lima Barreto et Gilton Mendes dos Santos, « As cores umuri masã no traçado das mãos de Feliciano Lana », Journal de la Société des américanistes [En ligne], 106-2 | 2020, mis en ligne le 30 décembre 2020, consulté le 16 septembre 2022. URL : http://journals.openedition.org/jsa/18901 ; DOI : https://doi.org/10.4000/jsa.18901 


\title{
As cores umuri masã no traçado das mãos de Feliciano Lana
}

\author{
Jaime Diakara (Dessana), Dagoberto Lima Azevedo (Tukano), \\ Justino Sarmento Rezende (Tuyuka), Silvio Sanches Barreto (Bará) \\ e João Paulo Lima BARreto (Tukano) \\ Texto compilado e revisado por Gilton Mendes dos SAntos
}

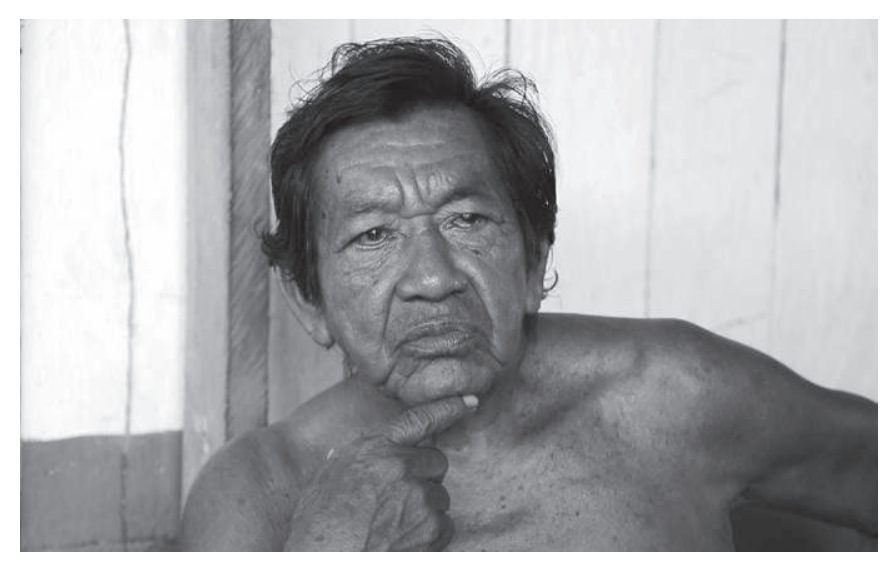

Fig. 1 - Feliciano Lana (Gustavo Soranz, 2020)

Entre os povos originários do noroeste amazônico, quando alguém deixa de viver nesse mundo, se realiza o cerimonial de despedida. Os moradores da aldeia se juntam aos familiares do falecido para chorar, em voz forte e alta, a despedida do morto. Ao longo deste choro são destacadas as suas qualidades, o tratamento dado à família, sua participação na vida da aldeia, sua alegria, sua habilidade para contar piadas, seu espírito de trabalho, sua disponibilidade para ajudar as pessoas etc.

* J. Diakara (Dessana): Doutorando, Universidade Federal do Amazonas [jaimediakara@ yahoo.com.br]; D. Lima Azevedo (Tukano): Doutorando, Universidade Federal do Amazonas [limaazevedo@gmail.com]; J. SARmento Rezende (Tuyuka): Doutorando, Universidade Federal do Amazonas [justinosdb@yahoo.com.br]; S. SANChes BARreto (Bará): Doutorando, Universidade Federal do Amazonas [basasi@bol.com.br]; J. P. Lima BARreto (Tukano): Doutorando, Universidade Federal do Amazonas [jplbarreto@gmail.com]; G. Mendes Dos SAntos: professor do Departamento de Antropologia, Universidade Federal do Amazonas [giltonmendes@ufam.edu.br]. 
J. Diakara, D. Lima Azevedo, J. Sarmento Rezende, S. Sanches Barreto, J. P. Lima

Barreto, G. Mendes dos Santos

Feliciano Lana viajou deste para outro mundo. Pessoas que conviveram com ele, que conheceram sua obra ou que simplesmente ouviram falar dele realizaram o cerimonial de recordação, facilitado pela velocidade com a qual chegam as notícias pelas redes sociais.

Feliciano Pimentel Lana nasceu na aldeia São João Batista, no rio Tiquié, em 1937, estudou no colégio interno Salesiano, no Distrito de Pari-Cachoeira, casou-se com Joaquina Machado Tukano, e passou a viver na cidade de São Gabriel da Cachoeira/AM a partir de meados da década de 1990. Feliciano Lana faleceu no dia 12 de maio de 2020, em sua casa, na aldeia São Francisco, no Alto Rio Negro, vítima de parada cardiorrespiratória, com suspeita de Covid-19.

A presente homenagem prestada a Feliciano Lana é obra conjunta dos membros dos povos Dessana, Yepamasa/Tukano, Utãpinopona/Tuyuka e Bará. Somos pesquisadores do Núcleo de Estudos da Amazônia Indígena (NEAI), acadêmicos do curso de Antropologia no Programa de Pós-Graduação em

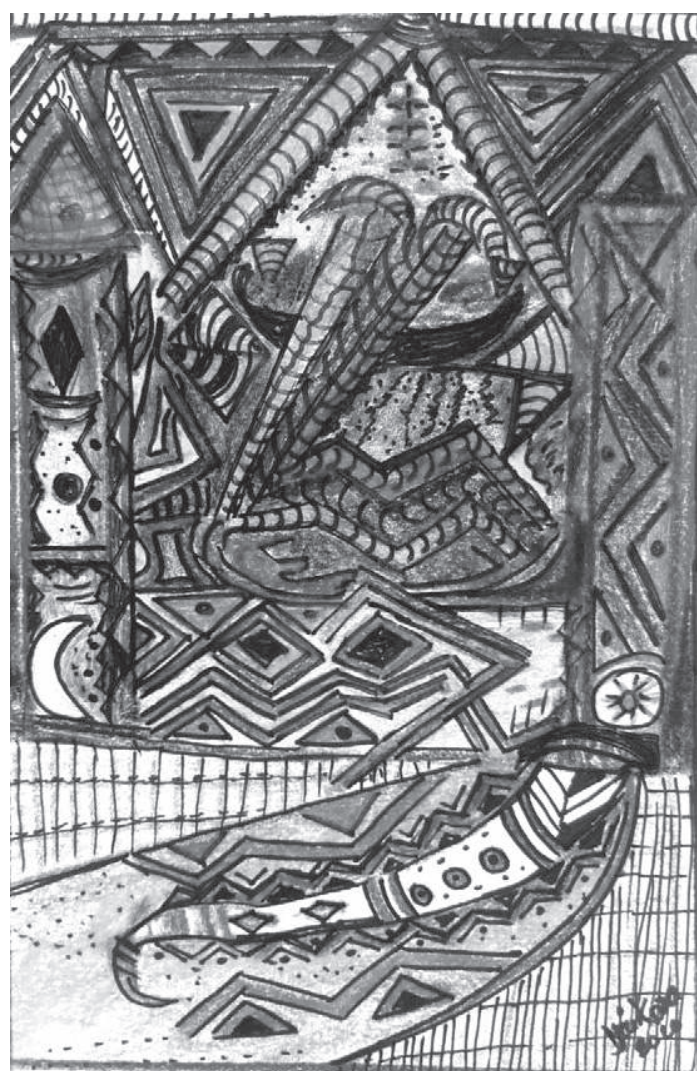

Fig. 2 - Mundo do aparecimento (Jaime Diakara, 2020) Antropologia Social (PPGAS), da Universidade Federal do Amazonas (UFAM).

A pessoa de Feliciano Lana e sua obra representam o valor simbólico e antropológico que deverá perpetuar por gerações. Cabe a nós, descendentes dos povos originários do noroeste amazônicos, dar visibilidade e, ao mesmo tempo, vibrar com os conhecimentos de nossas culturas, com suas qualidades e habilidades próprias, como fez Feliciano Lana.

$$
* * *
$$

\section{Mahsa Buâri Pahti}

Ahte hori merã arĩ yükaweri wiĩrü mahkũ heriporã bahseke merã piisunoü arĩ Sibé (Feliciano Lana), Torãmü Kẽhori Porã küũ mahsabuâdiakã. Ahtiro niũsetirã parãmi nī̌kü buhtidiami niigüma, müsarẽ, ahto kãrõ bahpakiokeoti. Üsã wirã porã ũkũsetiro merã. 
Ümũkori Mahsa, pamũâti dihporore, ümũse pahtipü nĩ̃gũ. Ahte wiorẽ amotikũpũ, wiõ wĩ wegü ahte kahsere tüônari mahsu niĩpü, tehgü ahte bahsese bahsĩgüpü ari niĩsame wiõ mahsu niĩma. Pamũka behroma ahte gahpi burẽõrama, tehê mahsã uhpüko gahpidari sĩrĩü, ahte gahpi hori buâpeakãtiporo, tere ñaãdiokũ, wãkũnürõta, behro ahti mari katiri pahtiperema, ahtirota buâpü nĩ horikũmũãpü, bahsamori hori, wümati hori, uhpü hori, bahsabohta wii hori, kumũ hori. Ahtere hori buhsartigü mahsü niũsami arĩ Ümũkori Mahsa. Ahtokãterore ahtero kiosa mari. Ahtiro niũsetirã niũsa marĩâ niĩkũ yüpahkümi.

\section{Mundo do aparecimento}

Antes do surgimento do mundo, os Umzkori Masa (Gente do Universo/Dessana) viviam no patamar celeste. Seu principal veículo cósmico era o wihõ (paricá). Ao praticar o cerimonial de wihõ seus membros tornavam-se conhecedores de mundo. Dessa forma, o Ser do Wihõ era o conhecedor dos basese ("benzimentos"). Após o surgimento dos Dessana vieram os Pamuri Mahsa (grupos viajantes na Canoa da Transformação), que criaram e, juntos, sorveram o "líquido do caapi" e, assim, tiveram acesso ao mundo das cores e dos grafismos. Juntos, também, sondaram com profundidade o mundo em que vivemos. Por isso, eles são os autores originários dos grafismos e das cores utilizadas nas cerimônias rituais, das imagens dos do corpo humano, dos esteios e travessões da maloca. Por essa tradição mítica originária, herdamos esses conhecimentos. Assim me disse meu pai.

\section{Mahsa Diâ pahti}

Torãmü Kẽhori Porã arĩ Sibé (Feliciano) kũũ ñekũsumĩ miĩpĩrãko pohtepü, boânũkakü parãmi, tohpü bahsari wehkeâpü. Tehgü naã yâ kurama naã mahsami makũ niĩkü. Yüma yüü pahkü ahkabi mahkũ niĩkümi

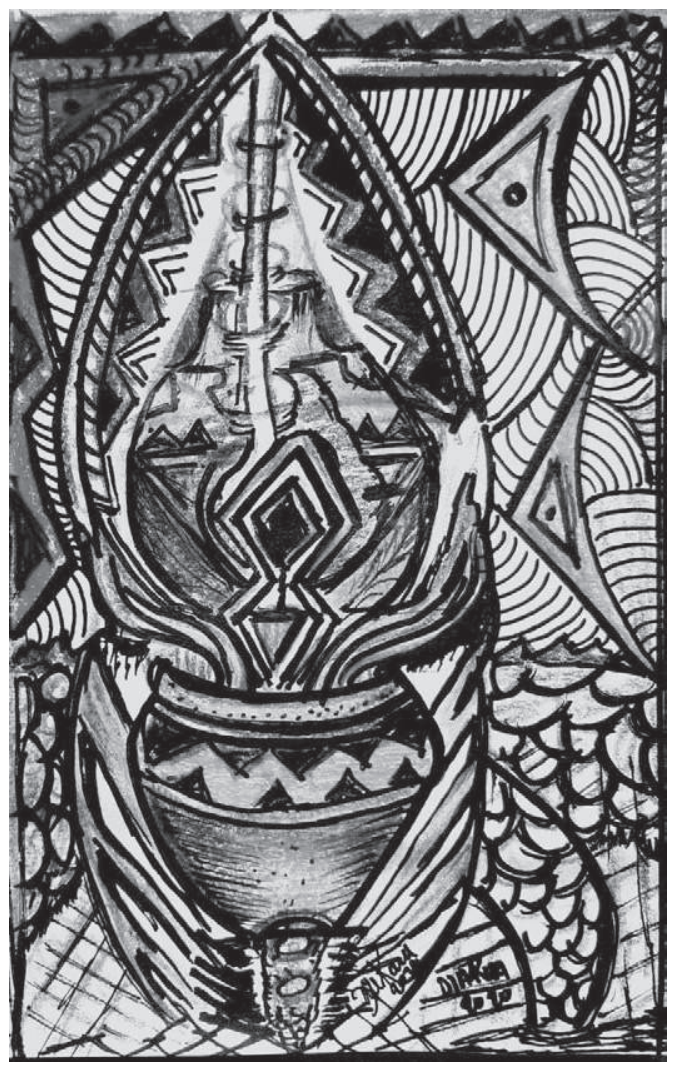

Fig. 3 - Mundo das águas (Jaime Diakara, 2020) 
niũmi. Ahrã pahíya hêase merã, warasakopé piânũkã mahka pããheâkarã niũma arã naã Torãmü Kẽhori Porã nĩ̃ ũkũma. Arĩ Sibé buküâtuheâguma, ahtirota wiĩmũ niũgũ, mükü uhpüri yü pahküre ñã̃, ũkũse tüô wehgü. Kihti küũ tüôkere meõ horikũ yüsa niĩgüma, hori ñakũkãakü nĩ̃wĩma, arã nĩ̃sama, naã bükürã ũkũrã niũgüma. Papera pũrĩpü kihti woâ tehê watero, ahte bükürã kihti, waimahsa kihti, yuküdüka mahsa kihti wehkũkü nĩ̃wĩma. Musa dahragü, arã pehkãsãpea, ahtiro dahragüma wiopesaro ñamana niĩgüma yüma tohô wiogü merã, ũkũwũ mühsare wehta mũgü wekãmikü, dehro niĩ wãkũti mühsa nĩ̃ serĩnawũ, yü̈̈ tonikã tüorã, mahkã dehko musa do lago nirõ parãma nãrẽ Feliciano wãkuãpa nĩ̃wĩ, wãemere kũ̃̃a nĩ̃wũ. Tohô niīkã tüôrãma küũ dahreke hẽõpeonowũma. Ahte küũ dahrakere ahti pahtikãrãre kũdiâmima. Tehgü ahte horire mahsãdiâ tünarõ merã wegü weâpü. Yüü pahkü wãkũgũ, yü pahkü mahsa diâ tüỗagü nãã mahsĩse merã naã buhtidiâka.

\section{Mundo das águas}

Feliciano Lana é conhecido tradicionalmente pelo nome Sibé. Ele é descendente de Torãmu Kẽhori, originário do Lago de açaí, onde localizava sua maloca cerimonial. Na compreensão do meu povo Dessana, Sibé é filho do irmão menor de meu pai Diakaru. Quando os missionários chegaram à região do Alto Rio Negro, seus avós fizeram uma aldeia no Lago Wará (frutas), e ali vivem até hoje os descendentes de Torãmu Kẽhori. Sibé aprendeu com meu pai alguns ensinamentos, e logo os transformou em desenhos e pinturas. Ele desenhou e também escreveu sobre nossos ancestrais, sobre os waimasa ("seres peixes"), as paisagens, os animais e as frutas. Quando eu trabalhei no Museu da Amazônia (MUSA), localizado na periferia da cidade de Manaus, percebi que os visitantes valorizavam muito a arte dessana. Assim, quando inauguraram uma nova sede do MUSA no centro da cidade, eu logo sugeri que levassem para lá os trabalhos de Sibé. Esta sugestão foi acatada, e hoje temos a alegria de contar com a obra do artista Feliciano Lana exposta neste Museu. Sibé nos deixou essa herança, e por isso meu desenho lembra esta história e faz uma homenagem a ele. Eu o fiz pensando também no meu pai, que faleceu no ano passado. Com meu trabalho e meus desenhos pretendo dar continuidade à arte do meu povo, à herança que recebi dos meus antepassados, à origem cósmica dos meus ancestrais e ao legado que nos deixou o parente Sibé.

Jaime Diakara

$$
* * *
$$

Na bacia do rio Tiquié, afluente do rio Uaupés, o internato dos Missionários Salesianos em Pari-Cachoeira, no auge de sua educação escolar, aglutinou os filhos de vários grupos étnicos existentes naquela região. A grade curricular era similar àquela das escolas dos filhos dos não indígenas da cidade. Além dos estudos, 
os padres investiram na qualificação dos indígenas para a prática da carpintaria, alfaiataria, marcenaria, mecânica, magistério, catequese e também de "capitão da comunidade". Aqueles que não seguiram os estudos e nem foram formados nessas profissões puderam optar, ou lhes restaram os aprendizados tradicionais, e tornaram-se reconhecidos como basegu (xamãs) e baya (mestre de cerimônias).

Uma vez profissionalizados, no entanto, os ex-internos não tinham como encontrar um emprego na região, o que os levou a retomar o aprendizado dos conhecimentos dos basera e a perpetuar a vida e a vivência dos povos Pamuri Masã e Umukohori Masã. Alguns ex-alunos, com o tempo, passaram a circular nas cidades da região e também em outras mais distantes, em diferentes estados brasileiros e também no exterior.

Nessa época começaram a aparecer na região os antropólogos, cujo trabalho era feito somente pelos missionários em suas descrições, anotações, documentações e outros registros. Sendo um ex-interno da Missão Salesiana, creio que Feliciano Lana tinha adquirido algumas noções de desenho e pintura no estilo não indígena. Com o tempo e o incentivo de alguns dos seus interlocutores, ele foi se aperfeiçoando nas técnicas e nas habilidades do desenho e da pintura. Nunca tive a oportunidade de conversar pessoalmente com ele, apenas ouvia falar e apreciava suas obras, expostas em vários lugares. Mas o legado do Umukohorimasu me faz pensar que, através da pintura, ele conseguiu mostrar e expressar a existência e a resistência dos sistemas de conhecimentos indígenas, de um mundo de significados para além do alcance da compreensão dos ditos "civilizados".

Dagoberto Azevedo

$$
* * *
$$

Os povos originários do noroeste amazônico, através de um de seus descendentes, Kenhiporã - "filhos dos desenhos dos sonhos", construiu pontes desde um pequeno lugar de nomes variados, como Amuarã (Akoãra) dihtara (Lago de piabas); Waraserako (Lago da fruta de nome wará) e São João Batista, até os diversos centros culturais e acadêmicos do Brasil e de outros países. Ele é um dos herdeiros dos conhecimentos dos povos do noroeste amazônico. Com a sua vida e a sua partida para o outro patamar existencial, deixa para nós, que ainda vivemos, e para as futuras gerações sua obra e sua arte.

Nesse momento, tento imaginar que ele deve ter acessado o mundo dos kapidoharã, os agenciadores da ayahuasca (caapi). São eles que, no plano metafísico, conseguem conversar com as cobras, e a elas pedem emprestado suas cores e seus desenhos corporais. Depois imergem no líquido do caapi essas cores e desenhos, que são acessados pelos homens que bebem o caapi. Conforme a preparação de cada um, no momento do kapibahuase, "com as mirações causadas pelo efeito do caapi", enxergarão as diversas cores do mundo, 
da maloca, das músicas e dos ancestrais Cobras; verão os esteios se transformarem em Cobras e virem conversar com eles; os esteios, os travessões e as palhas da casa falam pela voz de nossos ancestrais.

Os nossos bayaroa, mestres de danças, os kuтua, mestres cerimoniais, e os demais homens, ao beberem o caapi, acessam as mirações antes da festa, estampam os desenhos e as cores que viram nos esteios das malocas, nos bastões de dança, nos bancos, no chocalho, no pote da bebida, nos maracás e nas flautas. Expressam nas pinturas faciais e corporais dos homens e das mulheres as cores vermelho e preto. As cores ainda são encontradas nos tons de terra tabatinga (vermelha, amarela, azul, branca), nas tonalidades das penas dos pássaros (verde, azul, vermelho, preto, amarelo, marrom...), no colorido dos peixes, na tecelagem dos balaios e dos cestos.

Na sua trajetória de vida, como membro da Gente do Universo e dos "filhos dos desenhos dos sonhos", Feliciano Lana aprendeu esses conhecimentos através da educação de seus ascendentes. Andando por diversos lugares onde deixou a marca de suas pisadas, ele também acessou outros conhecimentos. A passagem ligeira pelo internato salesiano de Pari-Cachoeira não o impediu de continuar vivendo aquilo que aprendeu, pois havia nele uma educação dessana sólida. No internato salesiano era possível ver muitos jovens que faziam pintura de alta qualidade, chegando próximo do nível dos desenhos que se viam nos livros didáticos. Não era normal, porém, fazer os desenhos referentes às culturas originárias.

Feliciano Lana teve, certamente, um incentivo para produzir seus desenhos em outra direção. Não conheço muita gente, mas eu tenho que apontar três pessoas que, desconfio, foram seus incentivadores. O primeiro foi o Pe. Kazys Jurgis Béksta (Casimiro Béksta: 1924-2015), um salesiano de origem lituana, que desenvolveu um longo trabalho entre os Dessana, autor do livro A Maloca Tukano-Dessana e seu simbolismo (1988). O segundo foi a antropóloga Dominique Buchillet (1951-2018), que dedicou bom tempo de sua pesquisa e atuação àquela comunidade. A terceira foi a antropóloga Berta Ribeiro (1924-1997), que também atuou entre os Dessana antes de Dominique Buchillet. Feliciano Lana e seu irmão Luis Lana foram levados pelo entusiasmo e a dedicação dos antropólogos que atuaram entre os Dessana. Esses antropólogos não fizeram deles apenas seus tradutores e informantes, mas também trabalharam juntos com eles, tendo-os como interlocutores, e os tornaram protagonistas de suas próprias produções.

Feliciano Lana investiu na sua habilidade de artista, desenhista e pintor. O conteúdo de seus trabalhos expressa a história dos povos do noroeste amazônico. Seus desenhos narram sobre a nossa ancestralidade e a nossa sustentabilidade, que se expressam em cores diversas, e revelam-se em formas de Cobras Canoas, peixes, pássaros, onças, malocas, instrumentos cerimoniais, de danças e demais 
materiais. Mostram a conexão existente entre o mundo humano e os mundos de outros seres. As pinturas de Feliciano exprimem como ele imagina que é o mundo narrado por seus avós e retratam os seres de que ele ouviu falar. É algo feito com muita naturalidade, pois não existe um "professor" para controlá-lo, para dizer « melhore aqui », « faça diferente ». Ele gera suas artes engravidadas por muitos povos do noroeste amazônico. Ele mostrou para o mundo e para a academia uma novidade na organização e na transmissão de conhecimentos.

Sua trajetória de vida, sua arte, seus desenhos e pinturas inspiram-nos a mostrar os nossos conhecimentos para além dos esquemas preestabelecidos. Sua arte nos auxilia a pensar em novas formas, a construir, com originalidade, a expressão dos conhecimentos de nossos povos. Para nós, acadêmicos de antropologia, mas também de outras áreas do conhecimento, torna-se uma exigência repensar novos modos de organização e apresentação de nossos trabalhos. Desta forma, as contribuições deixadas por Feliciano Lana são inspiradoras. Os traçados das mãos de Feliciano Lana seguem vivos em nossas vidas.

Justino Sarmento Rezende

$$
* * *
$$

É uma honra para mim falar de Feliciano Lana, o que ele é, o que representa para o conhecimento do universo indígena e para as novas gerações. Ele não é qualquer um que se foi... Eu reconheço minhas limitações para falar com detalhes sobre nosso saudoso parente dessana, mas vou registrar aqui em algumas poucas linhas tortas. Muito antes de mim, ou melhor, muito antes de nós, antropólogos indígenas, da família linguística Tukano Oriental, já havia uma metodologia de construção de conhecimento oral através da arte, do desenho e da pintura. Antigamente, nossos pais se reuniam na calada da noite para conversar, para mascar o ipadu, o pó da coca, para fumar e para partilhar os conhecimentos. Essas pessoas transmitiam os conhecimentos do que haviam escutado de outro sábio. Fico imaginando os momentos propícios de aprendizagem repassada de pai para filho quando se está aquecendo perto do fogo, na pescaria, ao longo do caminho da roça e no momento de apanhar folhas de coca. Quando percebem alguma intervenção, é o fim da conversa e o fim da transmissão. Tenho certeza de que Feliciano Lana teve a oportunidade de receber essa transmissão, o que soube muito bem expressar em sua obra. Pelo que se sabe de nossos antepassados e de nossos especialistas (kumú, bayá e yâ̂), desde a criação do mundo já havia a presença da arte expressa nos ornamentos, na pintura das paredes da Casa Ritual, nos esteios da casa coletiva, nos instrumentos musicais e na pintura facial e corporal. Mas foram os "filhos do Universo", os Dessana, os pioneiros nessa arte, trazendo essa forma de linguagem para transmitir os conhecimentos. Tenho certeza de que Feliciano Lana está, agora, ricamente ornamentado na Casa do Universo, onde 
foi recepcionado pelos seus ancestrais. Eis aqui, tio, algumas linhas tortas em sua homenagem do seu sobrinho Wa' î pino pona Mahú.

Silvio Sanches Barreto

$$
* * *
$$

Eu cheguei a conhecer Sibé (Feliciano Lana) na minha infância, no Distrito de Pari-Cachoeira, durante as festas de Natal, de Páscoa, festas para Dom Bosco e de Nossa Senhora Auxiliadora, e nos festejos do dia 7 de Setembro. Tempos de concentração de toda a população da região no Distrito para comemorar essas datas. Lembro-me que Feliciano Lana era muito amigo do meu pai, porque eu os via conversarem bastante quando se cruzavam nos corredores do colégio interno e nas ruas do distrito.

Quando se encontravam, conversavam somente assuntos necessários, sem rodeios e brincadeiras. Era uma relação de cunhados, de parentes afins, portanto, de respeito e cercado de cuidado nas falas. Eu, acompanhando meu pai e minha mãe, via Feliciano Lana como um senhor calmo, de fala serena e de sorriso discreto.

Depois que saí do Distrito de Pari-Cachoeira, onde passei minha infância, para seguir meus estudos na capital, em Manaus e em outras cidades, nunca mais vi Sibé. Ele também acabou por sair da região, vindo a morar na sede do município, São Gabriel da Cachoeira, em razão de uma nova configuração econômico-político-social.

Depois desse tempo, passei a reencontrá-lo indiretamente por meio de seu trabalho, de seus desenhos, de seus livros, nos agradecimentos e nas citações de dissertações e teses acadêmicas. Mas no decorrer dos últimos onze anos que comecei a ter contato mais direto com os seus kahpihori (desenhos).

Imagine-se entrando no Museu Amazônico, em Manaus, para visitar a exposição dos desenhos de Sibé. Estão ali expostos os quadros de seus desenhos numa sequência lógica dos kihtiukuse (narrativas míticas) de origem de alguns povos indígenas do Alto Rio Negro. Logo na entrada, encontra-se um quadro da cobra grande, com um homem em pé em sua cabeça, segurando um bastão. A cobra navega pelo imenso rio, contornado de praias e florestas e sob um céu coberto de nuvens. Ela está toda pintada, com algumas partes do corpo divididas em pequenas janelas, nas quais se nota a tripulação dos futuros humanos. Mais adiante se vê outro quadro, com dois pássaros voando e levando uma criança numa rede. No fundo, entre as nuvens, nota-se uma "maloca" cercada por um pequeno anel de floresta, e o restante do quadro é preenchido pelas águas de um longo rio e de uma imensa floresta. Mais adiante vê-se outro quadro, uma serpente, ornada com grafismos no corpo, engolindo uma pessoa. E, assim, outros quadros vão se apresentando na exposição do Museu. 
Alguém que não está familiarizado, e sem um guia informado para explicar-lhe o sentido daqueles quadros, pode facilmente interpretar que aqueles quadros são desenhos da representação de uma imaginação, ou desenhos de sonhos, ou ainda admirar os desenhos como expressão do "espírito" do artista plástico. Mas alguém familiarizado com estas imagens, ao ver estes quadros, logo saberá que eles estão tratando dos kihtiukuse, das narrativas míticas dos povos indígenas do Alto Rio Negro, mais especificamente os povos denominados de Pamurimahsã. Assim, esses desenhos (kahpihori) levarão seu apreciador ao universo dos kihtiukuse (narrativas míticas), ao bahsese (arte do "benzimento") e ao bahsamori (conjunto das cerimônias). Dessa forma, os desenhos de Sibé não são meras representações de um imaginário, de um mundo de sonhos, mas um esforço de "imprimir" uma teoria nativa. Os desenhos agora tomam o sentido mais profundo de kahpihori. Os especialistas indígenas do Alto Rio Negro chamam de kahpihori todos os registros gráficos, que estão inscritos nas pedras ao longo do rio Amazonas, do rio Negro e do rio Uaupés, nos lugares denominados de PamuriWiseri, também conhecidos como "Casas Sagradas".

Kahpihori são expressos também nas paredes e nas colunas das casas coletivas, na cestaria, nos adornos e nos corpos. Os especialistas dizem que eles são a "chave" para acessar a realidade "metafísica", o que normalmente acontece durante as sessões de kahpi, nas sessões especiais de wiõ (paricá) e durante o período de formação de um novo especialista.

Assim, os kahpihori (desenhos) de Feliciano Lana não são simplesmente desenhos, ou desenhos simples. Por trás deles está expressa uma teoria indígena de explicação sobre o surgimento do mundo terrestre, dos humanos, das paisagens, dos seres, dos rios, dos peixes e de todos os demais animais.

Além dessa carga significativa, esses desenhos também carregam elementos considerados vitais pelos especialistas do Alto Rio Negro, pois eles evidenciam um conjunto de práticas sociais, de regras, de etiquetas e discursos formais durante as cerimônias. Estes elementos são também ingredientes das fórmulas de bahsese ("benzimentos") para a construção da pessoa, de cuidados do corpo e da qualidade de vida.

Com seu estilo de desenho inconfundível, Feliciano Lana, como um legítimo kahpihorimahsu, se esforçou para revelar um complexo conhecimento indígena numa linguagem acessível a um público não especialista, enfim, ao mundo dos não indígenas. Ele exprimiu todo esse conhecimento complexo do Alto Rio Negro na forma de desenhos. Por isso, ele ocupou um lugar importante como embaixador do mundo indígena, na medida em que este "idioma" dos desenhos simples, muitas vezes confundido como um padrão infantil, sem muito rigor estético-acadêmico, revelou, no papel, toda uma teoria nativa a um grande público, que ainda está por entender a profundidade do seu trabalho. Por tudo isso, ouso chamar Feliciano Lana de kahpihorimahsu, o "Ser das imagens", mas não de quaisquer imagens. 
J. Diakara, D. Lima Azevedo, J. Sarmento Rezende, S. Sanches Barreto, J. P. Lima Barreto, G. Mendes dos Santos

Nessa oportunidade, aproveito para homenagear também todos os kahpihorimahsã (seres de desenhos) que estão vivos, tomando como referência meu amigo Torãmū (Jaime Diakara), aqui presente neste texto de homenagem, em nome de todos os outros.

João Paulo Lima Barreto

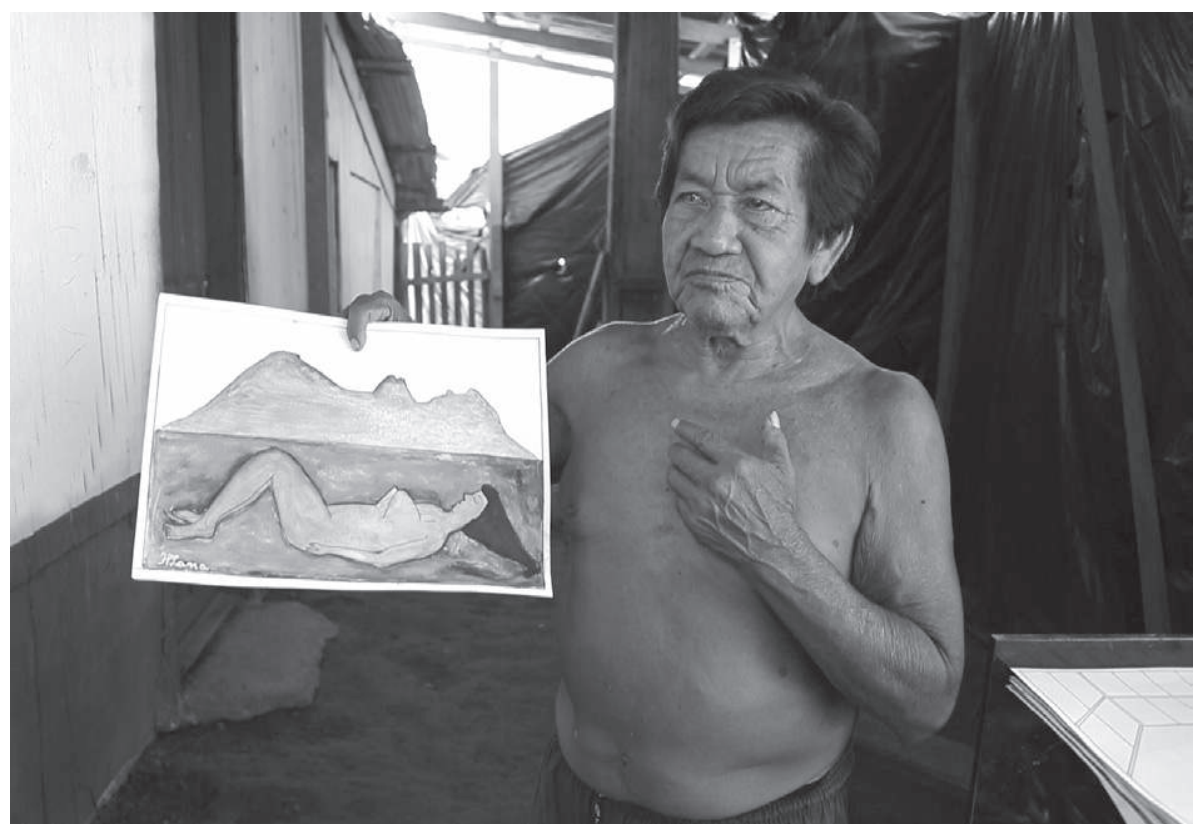

Fig. 4 - Feliciano Lana (Gustavo Soranz, 2020) 